\title{
Blogging in and about the Workplace: A Linguistic and Discursive Analysis of Work Psychology Discourse and Discourse Communities
}

\author{
Roxanne Barbara Doerr \\ DOI: http://dx.doi.org/10.7358/lcm-2017-001-doer
}

\begin{abstract}
Work psychology focuses on how people think and behave at work by applying psychological concepts and methods to reflect on work, the workplace and the workforce. Its relevance has increased and changed in the light of globalization, as well as the dematerialization and mobilization of the workplace and the development of new sectors, services and media. Moreover, the use of social and new media for the dissemination of knowledge regarding recent changes in employment trends and procedures have led to an open and democratizing shift in power of and over workplace discourse, allowing hitherto marginalized professional figures to voice their needs and experience to objective peers and advisors. This opening and sharing of discourse within a perpetually connected worldwide community has raised questions about where a workplace's boundaries lie and the contexts in which a worker may be considered an employee or an individual communicating online in and out of the office. The present preliminary study therefore analyzes a significant and adaptable online genre, i.e. work psychology blogs, to observe and consider how experts on workplace mentality apply rhetorical devices and discursive and linguistic strategies to inform, encourage and influence the perception of employees within online discourse communities.
\end{abstract}

Keywords: blogs, discourse community, globalization and transnationalism, language and social media, workplace discourse, work psychology.

\section{INTRODUCTION: A WORKING DEFINITION OF WORK PSYCHOLOGY}

The present study focuses on work psychology and the popularizing dissemination of its most recent and practical ideas in blogs, where work psychology specialists present themselves and their field of work and seek 
to help employers and employees. Today's connected and dematerialized worldwide community has raised questions about the workplace's boundaries and the worker's role. The former has become less material and is defined to better accommodate the increased mobility of work and working thanks to practices like workshifting, working from home and shared workspaces: it is increasingly common to hear and read of 'work spaces' instead of 'workplaces' where professional duties and tasks are executed in common areas, public places or even on means of transportation rather than a traditional office or established location. This expansion of professional activity and work activities has had great impact on organizational training and development programs (Derks and Bakker 2013, 1). These developments have been both the object of study and the result of work psychology: its main aim in fact is to inquire into how people think and behave at work by applying psychological concepts and methods to reflect on work activity, the workplace and the workforce, thus identifying problems and solutions. The ongoing development of the field is attested by the fact that its name has changed in accordance with developments in the conception of work and working subjects. It has gone from being centered on the traditional idea of workplace, with terms like 'industrial psychology' and 'industrial and organizational psychology', to becoming more people-oriented, as implied in expressions like 'occupational psychology' and 'business psychology' whose intent is not only to optimize work efficiency, but also to improve life, behavior and experience at work. Moreover, work psychology involves all of the phases, necessities and operations that are related to work in general and its institutional and interactional order.

The role of the worker has also changed and become increasingly dematerialized in time: professional activities take place between people who are physically very distant and even located in different time zones. Not only do more and more professionals provide immaterial services and products, but they have also become sought after as proactive "knowledge workers" (McInerney 1999), whose value consists in their competitive spirit of initiative, as well as their personal and intellectual conception and elaboration of information, rather than mere execution, of orders. This information is in turn seen as an important resource that may be disseminated and further developed within the workplace or even the professional discourse community, often by means of online communication. The possibility to work outside of the office has also led people to bring their work, with its rewards and problems, to their homes and their free time. Hence the need of work psychologists to consider the mutual influence of people's professional and private lives. As a result, research in and on 
work psychology involves numerous sub-audiences and identities in various professional positions (managers, representatives, employees, candidates) which are considered both as individuals and as subjects working within organizations and with other subjects (colleagues, teams, opposite numbers, hierarchy) (Kegan and Lahey 2001).

Discourse and interaction within and in relation to the professional world therefore come to the fore, along with the various linguistic genres and registers that have been created and developed to express and suit the working world's evolving needs (Drew and Heritage 1992; Nardi et al. 2004; Giltrow and Stein 2009). The previously mentioned expanded mobility of employees in time and space goes hand in hand with innovation in communication technology and its consequent ability to allow people to communicate quickly and on demand at any time and place. To compensate for this "placelessness", these means of communication tend to be characterized by language establishing "placeness" (Myers 2010, 9 and 48): therefore, the location in which the text is written or to which it refers is specified due to legal requirements, in the case of remediated texts (like in PDF documents), or by the writer either explicitly (by indicating it in his or her profile or openly mentioning where he or she is at the moment of writing) or implicitly by means of deictic expressions, or references to elements or situations that were, are or will be present at that place. As far as workplace communication genres are concerned, they may consist in the online remediation of traditional 'paper' genres, as in the case of PDF documents or PowerPoint presentations, which have replaced trasparents and posters, or in the use of 2.0 genres, such as blogs and podcasts, in and for the workplace. The term 'interaction' will be used here as a synonym of 'interactivity', consisting in "reciprocal communication exchanges that involve some form of media, or information and communication technology" (Bucy 2004, 375; original italics). The changes in discourse and interaction that have been brought on by the blog genre are also reflected in the approach and position of those writing, as will be demonstrated further on. As a result, although the fields of work psychology and linguistics have never interacted directly in interdisciplinary research, the following section of this pilot study will aim at arguing the current relevance of work psychology and its resulting online communication. The subsequent application of discourse analysis to popularizing work psychology blog posts will then exemplify how this emerging form of workplace communication often draws upon an array of familiar interpersonal linguistic and discourse strategies that are typical of online communication in its endeavor to better understand and analyze today's evolving work environment and lifestyle. 


\section{BACKGROUND: ONLINE COMMUNICATION IN THE WORKPLACE}

The role of communication - and in particular that of computer mediated communication and its texts - in the workplace has been greatly emphasized in the light of globalization, the dematerialization and mobilization of the workplace, and the development of new sectors, services and media around the world. This is due to the fact that it has added new issues such as relative anonymity, reduced importance of physical appearance, attenuation of physical distance and greater control over the time and pace of interaction (McKenna and Bargh 2000; Guadagno, Okdie, and Eno 2008, 1994). This expansion has contributed to an ongoing democratizing change in power of and over discourse concerning the workplace, as testified by the expansion of new and social media which have become an important tool for companies, employers and employees alike (Koester 2006 and 2010; Guadagno, Okdie, and Eno 2008; Baker et al. 2011; Polito 2011; Derk and Baaker 2013). On the one hand, the Internet and its means may be used to boost company value and legitimacy (Coovert and Thompson 2014) by promoting its activity through advertisements, strategic self-presentations and a variety of social media and their multimodal content. On the other hand, it could be perceived as a promising and empowering tool for employees and hitherto marginalized professional figures who can now voice their own needs and stories (Garzone and Catenaccio 2009). This voicing, and possible resulting dialogue, connects the work environment to socio-semiotic theories of communication, in which members of a cohesive community "are able to contribute to common purposes by dealing productively with constantly new cultural, semiotic and social problems by designing, representing and communicating their suggested solutions to them" (Kress 2010, 18). Moreover, they enable the negotiation and mediation between professionals with different roles and identities from the same or different fields and companies, which in turn promotes relationship-building (Koester 2010). This opening and sharing of discourse within a perpetually connected worldwide community has raised questions about where a workplace's and worktime's boundaries lie and where a worker goes from being an employee to being an individual and how this impacts online communication between professionals and peers (Baker et al. 2011; Stopfer and Gosling 2013).

Another important development that has impacted on the introduction of ubiquitousness (Mautner 2005) in online workplace communication is the phenomenon of the "domestication of technology" (Berker et al. 2005; Barton and Lee 2013, 2), which consists in the adoption of media technology in everyday life and in a domestic context, and has led to using online communication and its tools at home as well as at work (Bucy 2004; 
Barton and Lee 2012). This is in line with the above mentioned dematerialization of the workplace and also explains the spreading discussions on the workplace and its related lifestyle issues in more personal genres of new and social media communication such as blogs. Blogs in fact have gradually become fundamental widely accessible points of reference and knowledge dissemination for developing fields and issues "by highlighting articles that may easily be passed over by the typical web user [...], by searching out articles from lesser-known sources, and by providing additional facts, alternative views, and thoughtful commentary" (Blood 2000). They also provide potentially unlimited space for information, discussion and details that require personal time and space to be regularly updated (for more on the attributes of blogs, see Blood 2000; Bruns and Jacobs 2007; Puschmann 2010). Accordingly, those interacting online about work often tread the fine line that recalls Goffman's ([1959] 1990) division between a person's "front region", which is focused on his/her role and impression in society, and his or her "back region" which is perceived as hidden or private and where one can be his/her self, as for instance in their home. A hybrid context such as that provided by blogs, for " $[\mathrm{B}]$ logging concurrently makes it possible to be more social than ever [...] and as intimate and personal as a diary hidden beneath one's bed" (Tan 2008, 147). They may therefore blend the two 'regions' and encourage an equally hybrid register on the part of experts and professionals when writing in their blogs. Bloggers present themselves as helpful and friendly people who put their knowledge and experience at other people's disposal, thus providing necessary immaterial know-how and skills (Nardi et al. 2004). The resulting discourse is therefore more 'conversational' and relaxed, like the web 2.0 language in general, without shedding any doubt on the bloggers' competence and professionalism.

Thanks to workplace psychology, blogs that specifically analyze the workplace and its improvement have many aims such as those of informing, instructing, introducing research and studies, gathering information and stories, promoting initiatives, events and communities (both online and offline) and encouraging others to change for the better. Therefore, this ongoing change in online discourse and discourse communities enacts important community and identity-related changes both on a personal and collective level (Sergeant and Tagg 2014): as regards the former, knowledge through blogs and other forms of workplace media becomes a means of increased self-awareness, individualism and empowerment, for the employee is now aware of problems, solutions, methods and places or people to turn to in cases of need (Kress 2010). Moreover, studies have proved that interactivity entails presumed benefits including "increased 
acceptance, satisfaction, learning and mastery; enhanced thoughtfulness, cooperation and responsibility; and heightened performance, motivation, and sociability" (Bucy 2004, 374). If used correctly therefore, connections with blogs such as the ones analyzed here could prompt positive values such as self-discipline, motivation, autonomy, optimism and individual elaboration of data and experience on the basis of active information-seeking. The latter level, i.e. the collective one, consists in the potential sense of group identity that could link a worker with an alternative online community in addition to, or in substitution of, his/her everyday offline workplace community. Blogs are a place where one reads of other situations to reflect on an immaterial but always present reservoir of security, information and empathy (Koester 2010).

\section{AIMS AND METHOD}

The present preliminary study will focus on comparing two examples of a significant and adaptable online genre, i.e. work psychology blogs, from a discourse analysis perspective. First, special attention will be paid to the bloggers' online self-identification and the description of the aims of their online activity, i.e. disseminating knowledge and providing resources to employees and employers in order to empower them within an online discourse community. Afterwards, the study will observe which linguistic and discursive means typical of conversational and online language are employed to engage and sustain users through the application of workplace psychology. The diversity of the blog genre is in fact well suited to websites' variety and bloggers' linguistic/discursive style. Blog posts appeal to a specific issue or set of issues and aim to influence working subjects' perception of their own value inside and outside of their professional environments through different kinds of texts (descriptive, narrative, argumentative), rhetorical devices and linguistic features. The studies, proposals and ideas that are introduced in the blog entries are especially important when considering their potential impact on job performance, interaction in the workplace and communication in today's international and specialized job market and discourse community. For these reasons, the present preliminary study will attempt to address the following research questions:

- How do the blogger(s) approach and position themselves in relation to the issues and subjects related to the field of work psychology that they are introducing and discussing in their posts? 
- Which linguistic and functional means are used by the blogger(s) to address the blog's target audience?

The first research question is answered in $\S 4$, which introduces and describes the blogs under analysis and their position in relation to the field of workplace psychology, as well as in $\S 5$, as it is essential for bloggers to create an initial connection with the reader and attempt to gain his/her trust and loyalty (Bucher 2005). The second and most specific research question is the focus of $\S 6$, which concentrates on the posts themselves. After addressing these three important discursive fields, some observations on the implications and limits of the study are considered and some preliminary concluding remarks on the relevance of work psychology and its discourse analysis are presented.

\section{Data SET}

The data analysed in the present empirical study is drawn from the blogs of two websites that specifically deal with work psychology:

- Workplace Psychology: the Science of People at Work (WP): 1 blogger, 7 posts (approximately 9,378 words, introductions included), all referred to employers (http://workplacepsychology.net/).

- Minds for Business: Psychology Science at Work (MB): 3 bloggers, 65 posts (approximately 27,973 words, introduction included), divided into:

- Posts referred to business and organization: 26 posts;

- Posts referred to employees and individuals: 39 posts;

(http://www.psychologicalscience.org/index.php/news/minds-business).

The texts were collected in the period between January $1^{\text {st }}, 2015$ and October $31^{\text {st }}, 2015$. As this is an introductory qualitative pilot study, the size of the present corpus has been circumscribed to two similar and easily comparable websites and their online content. The websites were chosen on account of their popularity and search position, the number and consistent updating of their posts and their variety of topics. In order to see whether there is any particular change in self-presentation and self-identification in comparing individual and group blogs, one blog - the former - has been chosen from those written by a single blogger while the latter is managed by a group of experts. Both websites and blogs are managed by experts in the field of work psychology and its fields of specialization, and both are examples of what Puschmann terms "employee blogs / blog hubs", for they are "self-initiated and not started as part of a mandated company strategy" (Puschmann 2010, 100), although the Minds for Business: Psy- 
chology at Work blog also contains posts on business organization and management that could be compared to Puschmann's category of "executive blogs" (2010,99). Interestingly, both websites and blogs contain the word 'science' in their titles, recalling the academic/scientific sources that are referred to and the approach they are attempting to take. Recourse to the word 'science' gives the blogs, as well as its portrayal of workplace psychology, a sense of importance and reliability that may not be attributed by expert and non-expert users who are more sceptical about psychology and the relevance of its application in the workplace. The present study carries out a qualitative linguistic and discursive analysis that will be illustrated in the following sections. It focuses on the bloggers' posts and some of the introductory sections of their relative websites to better clarify the blogger(s)' position and main area(s) of interest.

\subsection{Workplace Psychology: the Science of People at Work (WP)}

This blog is run by an individual blogger, who presents himself with his name and title (Steve Nguyen, $\mathrm{PhD}$ ) twice in two different tab sections, i.e. "About me" and "Steve Nguyen, PhD", although in slightly different ways. Interestingly, in the former page, whose title would seem more informal and personal, he is introduced with less information and as a professional, while in the latter, which on the other hand would seem more professional since it presents his name and title, Steve Nguyen is described as an individual, with narrations of his family and personal life story. Moreover, the latter includes emotionally charged expressions like "By the grace of God", or complete sentences such as: "Dr. Nguyen's refugee experience was an invaluable lesson in courage and determination, while his life in the United States afforded him hope, taught him gratitude, and instilled in him an entrepreneurial spirit". Such communication is also expressed through his very clear presence in his writing by means of personal pronouns, opinions and indicators of stance.

Dr. Nguyen's blog is focused on employers and managers, except in the "About this site" section which addresses workers in general, and on three specific areas that concern both employers and employees (industrial-organizational psychology, occupational health psychology and organizational behaviour). By proposing the perspectives and interests of both employers and employee, the blog implicitly attempts to negotiate between these two sub-audiences. The blogger is a Leadership and Change Consultant, who therefore deals with employers and employees by informing both on what could be done to improve the work environment and 
interprofessional relations for all involved subjects. Moreover, he intends to fill in the general gap of expert knowledge in an approachable way, thus becoming a point of contact and reference both through his own work (like in the "Academic Writings" section of the website) and through those of others (in the "Resources" section). As a result, there is a great amount of intertextuality and hypertextuality to encourage knowledge sharing and networking, as may be seen in the "Blogroll" section, the hyperlinks in articles and the references that are provided at the end of every post.

\subsection{Minds for Business: Psychology Science at Work (MB)}

The second blog is run by a small group of bloggers belonging to the Association for Psychological Science and therefore represents a popularising appendix of an official establishment. This different position and the fact that there is a team behind it allow it to have a much more complex structure, in comparison to the previous blog. In fact, it covers many activities related to work psychology (teaching, employment, students, conventions, publications) and presents varied media and genres (videos, press releases, publications, social networks, podcasts) which are provided for diverse categories of workers (employee network, members, students, teachers and other people who have made significant contributions). It also aims at creating an interactive and productive online community by offering the audience the possibility of becoming a member; this possibility further reinforces the idea of community and encourages interested users to continue reading and therefore become loyal, participating members. The variety of users and topics is also guaranteed by the blog's balanced points of view, for it considers the perspectives of both employees and businesses and therefore serves the informative needs of different and apparently opposed groups, who may both learn from within their interests and about how other subjects approach issues that are important to them.

Like the previous blog, the Minds for Business blog is also an informative outlet used for disseminating publications on the latest theories and ideas published both by the Association for Psychological Science and other academic sources. The posts themselves take on an academic structure by following the IMRaD (Introduction, Methods, Results, and Discussion) format as well as providing considerations on the implications and limitations of the studies or experiments at hand (which is what more practical users are interested in) and references at the end of each post. Incidentally, the bloggers facilitate non-academic readers by briefly but concisely explaining all of the technical terms for workers. 


\section{COMMUNity OBJECTIVES AND BLOGGERS' SELF-POSITIONING}

As previously mentioned, the subject(s) behind the analysed blogs are different and therefore present themselves differently. This affects their degree of 'approachability' and influences the impression a user has of the blogger's personality as an individual and a professional because, as Leon Tan points out, the blogger must make some investment and adjustment in order to find a suitable community to which he or she may contribute (Tan 2008, 151). Blogs have been considered an important tool for psychologists and professionals in general to access and help their patients and other people who may need their advice and assistance, and to disseminate information and helpful resources. Moreover, because it provides an environment that gives free space to the bloggers' studies and expert opinions, the language of their posts may change based on their affiliation, or lack thereof, with other associations. This is evident in focusing on the blogs' idiosyncratic introductions and self-presentations, which are very important because they clearly establish the blogger(s)' identity, intentions, tone and areas of research and interest. The WP blogger Steve Nguyen, for instance, presents his work as a focused source of information and discussion on specific areas of workplace psychology, and then justifies such a selection based on his personal interest in the effect(s) of such studies on everyday work life:

The focus of this blog is on Industrial-Organizational (I-O) Psychology, Occupational Health Psychology (OHP), and Organizational Behavior (OB). I am fascinated ${ }^{1}$ by the impact of work and workplaces on employees' health and well-being and vice versa, how employees' health and well-being affect their jobs. (http://workplacepsychology.net/about/)

The blogger's insertion of a first-person reference underlines his personal and professional contribution to the field through his activity, as well as the more person-oriented approach that he intends to adopt throughout the blog. The connotative use of the word 'fascinated', rather than a more neutral one like 'interested', also implies his personal involvement and investment in his work, and therefore hints at the extra care that he will take in performing his job as a work psychologist and a blogger.

The Minds for Business blog, on the other hand, presents a more impersonal approach to the field and therefore already emphasizes the amount and variety of information that will be provided:

1 In all examples, emphasis is added by the author unless otherwise indicated. 
The indispensable research blog on the science of the modern workplace, covering everything from leadership and management to the behavioral, social, and cognitive dynamics behind performance and achievement. (http://www. psychologicalscience.org/index.php/news/minds-business)

The term 'research blog' demonstrates that its goals are mostly projected towards future developments in the field, thanks to the consideration and analysis of current 'research'. The latter is not restricted as in the previous quotation, but rather refers to itself as a rich and comprehensive source of information and ideas by using the expression "covering everything from [...] to". Moreover, its intent is to be 'indispensable' and therefore a fundamental point of reference and connection to a group that is connected with the prestigious association that supports the blog that can satisfy needs that are linked to all of the mentioned issues. The language is inclusive and the bloggers refer to themselves as a team of professionals.

\section{LINGUISTIC AND FUNCTIONAL FEATURES}

As previously mentioned, the language of blogs has gradually taken on a popularizing and personable tone when attempting to connect and interact with the discourse community that turns to them. The members of the discourse community usually do not know each other and may not interact directly but only with the blogger(s) when and where possible. Blogs are "one of the newest forms of online self-presentation and selfexpression" (Guadagno, Okdie, and Eno 2008, 1994) and are therefore a sort of bulletin board which addresses one type of audience but actually aims at a much larger one composed of 'overhearers' and maybe even 'eavesdroppers' (Bell 1984). For this reason, the discursive strategies relied on here recall those used in everyday written and spoken interaction in order to attract, involve and convince readers and listeners not only on a professional but also on a personal level. This occurs because the cultivation of one's online voice through consistent and frequent posting on a blog "enables a reader to identify the characteristic x across a blogger's multiple posts over time" (Tan 2008, 151). It is even more obvious when considering that the level of informality of the blog's register does not match the one that is usually expected from a professional who is informing his/her selected audience on ongoing research trends in his/her field. Such a trend is becoming common in professional online blogging and online therapy and advice (Chamberlain and Hodgetts 2008; Tan 2008). The resulting popularizing language and discourses have become a way to 
instruct an increasingly demanding public that wants to understand and learn very specific information and procedures in a clear and approachable manner.

The blog posts will now be analysed more in depth from a qualitative perspective. Although blogs actually target and address a large and unknown audience, they do so by using the same tools that are generally employed to gain a specific individual's understanding, believing, attentiveness and trust (Bucher 2005). The most striking linguistic and discursive features will be listed and expounded on through significant samples. The focus will be on features that are typical both of popularizing literature, which is fundamental in disseminating knowledge of interest for diverse categories of employers and employees, and aim to give credibility to the innovative means through which such information is conveyed, i.e. blogs. The analysis will be carried out on a textual, discursive level and will focus on the signals that members of an online discourse community could most easily - and unconsciously - detect and relate with. Such signals will be analysed one at a time, with an explanation and related examples.

- Devices used to engage with the audience (Myers 2010): these are very common in conversational and popularizing literature and may take on different forms (direct addresses, pronouns, conversational interaction, implicature, shared expectation and knowledge). They have the manifold purposes of challenging preconceptions, proposing new ideas and situations and gaining the initial approval of readers and listeners by giving general statements they can relate to. This is accomplished through the use of inclusive pronouns and expressions that referred to ordinary people (such as 'anyone' or reference to categories like in the first two examples) as well as 'we/us', e.g.:

Anyone who's ever worked on their own project and see [sic] it through (from defining the initial problem to the project launch) will tell you the euphoria and sense of accomplishment (and relief) they feel. (WP)

When it comes to winning the office personality contest, extraverts seem to have the advantage. (MB)

We all need some advice sometimes. (MB)

- Time deixis: although blogs may be constantly updated, online writing may intentionally or unintentionally leave a linguistic print on its temporal position that remains in the blog post even with the passing of time (Myers 2010). If too subtle, though, it sometimes makes the sense of 
newness and reliability of articles and information vague. In place of or in addition to the date (and sometimes time) indicated in the post, this function may also be fulfilled by indications of a year (of studies and/or publications) or of a more or less defined past (as in the case of personal stories). Moreover, references to the past in contrast with the present indicate improvement or development:

After pivoting from the mental health field [...], I was naive enough to think that I would no longer need to tap into my counseling skills. Today, more than a decade after leaving my counseling life behind and much to my surprise and delight, I continue to find ... (WP)

In one experiment several years ago ... [...] More recently ... (MB)

- Interpersonal and conative language, conversational particles: the blogs often use engaging language that directly addresses the readers in a way that allows the blogger to write more informally, as if he or she were speaking or writing to a friend in a familiar manner. This allows the writer to present him or herself as an approachable helper with useful advice, and fits with the public's desire to learn important and complicated information in a simple and understandable manner. This is often accomplished through the use of inclusive 'we/us' as well as invitations, vocations and imperatives:

Let me share one example. (WP)

Brief 'takeaway' section at the end of each post. (WP)

The next time you run into a helpful colleague at work, you may want to thank them for being a friend. (MB)

- References to ongoing reader-blogger relationship and indication on presence: another way of creating a sense of continuity and loyalty in the blogger-reader relationship is the use of phatic expressions like those utilized at the beginning of some of Dr. Nguyen's posts. They are very common in individual-directed blogs (Myers 2010) and have an everyday social, rather than informative, function. This is possible and common when the blogger wants to be considered as a person and not only as a simple poster, and it also has the function of reconnecting old and new readers to previous posts (also through hyperlinks), thus proving his or her ongoing reliability or emphasizing the development that the concept or study in question has recently undergone:

I shared before about how I love Half-Price Books. (WP) 
Previously, I had written about Lominger's (now a part of Korn/Ferry) book. (WP)

- Stance modal verbs, idioms, evaluative adjectives: in order to write as an individual, the sole blogger of the Work Psychology blog would also add his personal impressions, using what Myers terms "stance modal verbs" (2010) which indicate the writer's opinion and state of mind. This personal and informal style of communicating proves that the blogger does not simply want to relay information, but also provide personal impressions, evaluations and input, as one does in everyday interaction. This is confirmed by the fact that the Minds for Business blog, being written by more than one blogger and presenting itself as an entirely objective and factual source, does not make use of these devices:

It is incredible to me how quick business people are to talk before hearing what the other person has to say. (WP)

There are certain words/phrases that irk me to no end - thought leader or thought leadership is one of them. (WP)

- Concessive constructs as antitheses of expectations: very often, when presenting new approaches or perspectives on commonly followed praxes or thought patterns, concessive constructs introduced by discourse markers like 'however', 'but' and 'yet' are used. This is the case in both blogs and it accomplishes Stöckl's 'yield' strategy (1997) to gain the user's consensus by seemingly considering opposing views and then providing a counterargument:

We have these grand illusions about working in our pajamas and wearing house slippers while we work. The reality, however, is that it requires a great deal of structure, time management and commitment [...] it actually requires you to work more, not less. (WP)

Employers might assume that a job candidate's financial history provides a real-world measure of their trustworthiness and reliability. However, new research contends that $[\ldots] .(\mathrm{MB})$

- Rhetorical questions: these are also used to attract attention, for "however uninterested one might be, it is hard not to project oneself in the role of responding" (Myers 2010, 82). However, they are commonly used when referring to an audience (i.e. in advertisements and speeches) and therefore may be efficient while remaining more impersonal compared to more individual-oriented techniques like conative language, phatic communication or stance expressions. For this reason they are often used 
in the group-administered and more 'official' Minds in Business blog. They may also be structured as a general question as in the first example below, or even as if the writer were putting him/herself in positions the reader could hypothetically be, or has been in, as in the second case:

But does bringing together the most talented individuals actually guarantee the best possible team performance? (MB)

Should I sign that contract? Should I fire that lazy employee? (MB)

- Second stories (Page 2012): in order to better relate the point of certain ideas, changes, situations or positions, the Workplace Psychology blog sometimes uses personal and success stories, which are easy to relate to and easy for the public to understand. It is often found in blogs, whose macrostructure (the chronological sequence of posts, Puschmann 2010, 52 ) is often narrative, in that it "blends, mixes and switches between narrative and non-narrative modes, but in which a total absence of narration is rare" (ibidem). Moreover, this allows the audience to better know the blogger and accept his perspective based on the fact that the assertion at hand has been tried out on the field. Since they are personal stories they are therefore entirely related in the first person:

In a previous life and time, I worked as a mental health counselor. I was trained in the art of listening and would periodically have my listening skills evaluated by professors, supervisors, and even peers (on videos and in live sessions). (WP)

\section{IMPLICATIONS AND LIMITATIONS OF THE STUDY}

The study contributes by focusing on an expanding subfield of psychology, i.e. work psychology, and suggesting how such an expansion may assist not only academics and professionals, but also a wide variety of other involved subjects (such as employers and employees) through its introduction to and application of new and social media. It also confirms the theory that psychological advice (not in substitution of therapy) may be provided online with great benefits both for professionals, who may help more people from a distance, and for those in search of advice, inspiration or other situations that resemble their own.

Although it is a preliminary qualitative study, it sought to glean some of the most prominent linguistic and discursive characterizing features of the websites studied and found that they linked the expert's professional 
knowledge with the engaging language of blogs. It also singled out differences within the genre of professional blogs related to the same field by comparing an individualistic blog and its blogger's position, as in the Work Psychology blog, with a more institutionalised and complex structure as the Minds in Business one. Such differences regarded not only the selfpositioning of the blogger(s) (or lack thereof), but also their choices of linguistic and discursive strategies, thus confirming that language is the reflection of online writers' identities (Garzone and Catenaccio 2009).

There were, however, limitations to the pilot study that could be the starting point for future inquiry, such as the need to compare more blogs and more extensive datasets, perhaps even contrasting ones that cater to the needs of different subjects (employees, employers, workers' unions, intercultural and international subjects) to verify discursive changes in stance, argument and knowledge dissemination. A further step could be to compare blogs that focus on the organization of one country or area (e.g. USA, the United Kingdom) and internationally-reaching ones, to see if and to which extent cultural differences in work practices and workplace culture may influence the linguistic and discursive strategies that are employed in online discourse communities regarding workplace communication.

\section{CONCLUding REMARKS}

By carrying out a qualitative analysis from a linguistic-discursive perspective, this preliminary study has attempted to introduce and demonstrate the potential and growing importance that workplace blogs may cover in the field of online workplace communication. This was done by considering two institutionally different but similarly popular and productive blogs that specifically dealt with work psychology and the issues and studies that would be of most interest to today's increasingly mobile and socially online workplace communication context, albeit from different positions (as a single expert or part of a recognized professional association). In the posts of these often updated and popular blogs, the study singled out some of the most distinctive and 'popular' linguistic and discursive means through which they contribute to creating and fostering an informed and empowered online discourse community. It has been proven that the new power of an online audience concerns their enhanced level of information seeking and distributing (Bucher 2005; Chamberlain and Hodgetts 2008). The blogs in fact not only inform but also contain a shared repertoire of diverse informative multimedia material (references, essays, slides, manuals, videos, 
PDF exercises) and necessary networking connections. Such connections may be created and referred to later on through some of the discursive devices mentioned above. It is also possible to create a different degree of distance and personal presence, as was proven by the varied online identities that were established by the blogger(s) of the two blogs. These blogs could also contribute to necessary and useful changes in the workplace by providing updated advice and information for managers and organizers on approaches and trends that have not been an object of extensive academic inquiry or management practice, as underlined by the frequent use of linguistic devices that highlighted changes in time and ongoing development of emerging workplace theories and practices in both blogs. Moreover, in order to help and convince the readers to read and follow their advice, the bloggers addressed the emerging needs of employers and employees both as workers and individuals in, around and outside of today's workplace also through emerging issues that mediate both categories by considering the challenges introduced by the current economy and job market that could unite, and not only divide, their interest and future work activities and practices.

\section{REFERENCES}

Baker, Douglas, Nicole Buoni, Michael Fee, and Caroline Vitale. 2011. "Social Networking and Its Effects on Companies and Their Employees”. Neumann Business Review (Spring): 1-14.

Barton, David, and Carmen Lee. 2013. Language Online: Investigating Digital Texts and Practices. New York: Routledge.

Bell, Allan. 1984. "Language Style as Audience Design”. In Sociolinguistics: A Reader and Coursebook (1997), edited by Nikolas Coupland and Adam Jaworski, 240 250. New York: St. Mattin's Press Inc.

Berker, Thomas, Maren Hartmann, Yves Punie, and Katie J. Ward, eds. 2005. Domestication of Media and Technologies. Maidenhead: Open University Press.

Blood, Rebecca. 2000. "Weblogs: A History and Perspective". Rebecca's Pocket. [20/05/2017]. http://www.rebeccablood.net/essays/weblog_history.html.

Bruns, Axel, and Joanne Jacobs, eds. 2007. Uses of Blogs. New York: Peter Lang.

Bucher, Hans-Juergen. 2005. "The Power of the Audience: Interculturality, Interactivity and Trust in Internet Communication. Theory, Research Design and Empirical Results". The Electronic Journal of Communication 15 (1-2). http:// www.cios.org/EJCPUBLIC/015/1/01511.html.

Bucy, Erik P. 2004. "Interactivity in Society: Locating an Elusive Concept". The Information Society 20: 373-383. 
Chamberlain, Kerry, and Darrin Hodgetts. 2008. "Social Psychology and Media: Critical Considerations”. Social and Personality Psychology Compass 2-3: 1109-1125.

Coovert, Micheal D., and Lori Foster Thompson, eds. 2014. The Psychology of Workplace Technology. New York - London: Routledge.

Derks, Daantje, and Arnold Bakker, eds. 2013. The Psychology of Digital Media at Work. London - New York: Routledge.

Drew, Paul, and John Heritage, eds. 1992. Talk at Work. Cambridge: Cambridge University Press.

Garzone, Giuliana, and Paola Catenaccio, eds. 2009. Identities across Media and Modes: Discursive Perspectives. Bern - Berlin - Bruxelles - Frankfurt am Main - New York - Oxford - Wien: Peter Lang.

Giltrow, Janet, and Dieter Stein. 2009. Genres in the Internet: Issues in the Theory of Genre. Amsterdam: John Benjamins.

Goffman, Erving. [1959] 1990. "Front and Back Regions of Everyday Life". In The Presentation of Self in Everyday Life, 111-121. Harmondsworth: Penguin.

Guadagno, Rosanna E., Bradley M. Okdie, and Cassie A. Eno. 2008. "Who Blogs? Personality Predictors of Blogging”. Computers in Human Behavior 24: 19932004.

Kegan, Robert, and Lisa Laskow Lahey. 2001. How the Way We Talk Can Change the Way We Work. San Francisco: Jossey-Bass.

Koester, Almut. 2006. Investigating Workplace Discourse. London - New York: Routledge.

Koester, Almut. 2010. Workplace Discourse. London - New York: Continuum.

Kress, Gunther. 2010. Multimodality: A Social Semiotic Approach to Contemporary Communication. New York - London: Routledge.

Mautner, Gerlinde. 2005. “Time to Get Wired: Using Web-based Corpora in Critical Discourse Analysis”. Discourse \& Society 16 (6): 809-828.

McInerney, Claire R. 1999. "Working in Virtual Offices: Providing Information and Knowledge to Remote Workers". Library \& Information Science Research 21 (1): 69-89.

McKenna, Katelyn Y.A., and John A. Bargh. 2000. "Plan 9 from Cyberspace: The Implications of the Internet for Personality and Social Psychology”. Personality and Social Psychology Review 4: 57-75.

Myers, Greg. 2010. Discourse of Blogs and Wikis. New York: Continuum.

Nardi, Bonnie A., Diane J. Schiano, Michelle Gumbrecht, and Luke Schwartz. 2004. "Why We Blog". Communications of the ACM 47 (12): 41-46.

Page, Ruth. 2012. Stories and Social Media: Identities and Interaction. Routledge: New York - London.

Polito, Rabindranath. 2011. "Language and Power in Blogging: A Critical Discourse Analysis". International Conference on Humanities, Society and Culture. IPDER (20): 282-286. 
Puschmann, Cornelius. 2010. The Corporate Blog as an Emerging Genre of ComputerMediated Communication: Features, Constraints, Discourse Situation. Göttingen: Universitätsverlag Göttingen.

Seargeant, Philip, and Caroline Tagg, eds. 2014. Identity and Community on the Internet. New York: Palgrave Macmillan.

Stöckl, Hartmut. 1997. Werbung in Wort und Bild. Textstil und Semiotik englischsprachiger Anzeigenwerbung. Frankfurt am Main: Peter Lang.

Stopfer, Juliane M., and Samuel D. Gosling. 2013. "Online Social Networks in the Work Context". In The Psychology of Digital Media at Work, edited by Daantje Derks and Arnold Bakker, 39-59. London - New York: Routledge.

Tan, Leon. 2008. "Psychotherapy 2.0: MySpace as Self-therapy". American Journal of Psychotherapy 62 (2): 143-163. 